\title{
Angiotensin-converting Enzyme Inhibition Improves the Effectiveness of Transcutaneous Carbon Dioxide Treatment
}

\author{
BALAZS NEMETH ${ }^{1,2}$, ISTVAN KISS ${ }^{1}$, TIMEA JENCSIK ${ }^{2}$, IVAN PETER ${ }^{2}$, ZITA KRESKA ${ }^{2}$, TAMAS KOSZEGI ${ }^{3,4}$, \\ ATTILA MISETA ${ }^{3,4}$, PETER KUSTAN $^{3,4}$, IMRE BONCZ $^{5}$, ANDREA LACZO ${ }^{5}$ and ZENO AJTAY ${ }^{2,6}$ \\ Departments of ${ }^{1}$ Public Health Medicine and ${ }^{4}$ Laboratory Medicine, \\ Medical School, University of Pecs, Pecs, Hungary; \\ ${ }^{2}$ Zsigmondy Vilmos SPA Hospital, Harkany, Hungary; \\ ${ }^{3}$ Janos Szentagothai Research Centre, University of Pecs, Pecs, Hungary; \\ ${ }^{5}$ Institute for Health Insurance, Faculty of Health Sciences, University of Pecs, Pecs, Hungary; \\ ${ }^{6}$ Heart Institute, Medical School, University of Pecs, Pecs, Hungary
}

\begin{abstract}
Aim: To study the effect of carbon dioxide $\left(\mathrm{CO}_{2}\right)$ therapy on the nitric oxide (NO) pathway by monitoring plasma asymmetric dimethylarginine (ADMA) concentrations. Patients and Methods: Forty-seven hypertensive patients who underwent transcutaneous $\mathrm{CO}_{2}$ therapy were enrolled. Thirty healthy individuals were recruited for the control group. Blood samples were taken one hour before, as well as one hour, 24 hours and 3 weeks after the first $\mathrm{CO}_{2}$ treatment. Controls did not undergo $\mathrm{CO}_{2}$ treatment. Plasma ADMA levels were measured by ELISA. Results: ADMA levels decreased significantly one hour after the first CO2 treatment compared to the baseline concentrations $(p=0.003)$. Significantly greater reduction was found among patients in whom angiotensin converting enzyme inhibitors (ACEIs) were administered $(p=0.019)$. Conclusion: The short- and longterm decrease of ADMA levels suggests that $\mathrm{CO}_{2}$ is not only a vasodilator, but also has a beneficial effect on the NO pathway. ACE inhibition seems to enhance the effect of $\mathrm{CO}_{2}$ treatment.
\end{abstract}

Transcutaneous administration of carbon dioxide $\left(\mathrm{CO}_{2}\right)$, further referred to " $\mathrm{CO}_{2}$ therapy" has been used for curative purposes since 1932 (1). $\mathrm{CO}_{2}$ passes freely through membranes and has a well-known vasodilation effect. Both in vitro and in vivo studies have demonstrated a rightward

This article is freely accessible online.

Correspondence to: Balázs Németh, Department of Public Health Medicine, Medical School, University of Pécs, Szigeti str. 12. H-7624 Pécs, Hungary. Tel: +36 72536394, e-mail: balazs.nemeth@aok.pte.hu

Key Words: Carbon dioxide therapy, asymmetric dimethylarginine, angiotensin converting enzyme inhibitor. shift of the oxygen-hemoglobin $\left(\mathrm{O}_{2}-\mathrm{Hb}\right)$ dissociation curve after administration of $\mathrm{CO}_{2}$. This "artificial Bohr-effect" seems to be responsible for decreased $\mathrm{pH}$ and increased partial pressure of oxygen (PO2) demonstrated in tissues after $\mathrm{CO}_{2}$ therapy (2). These effects have been confirmed by Minamiyama and Yamamoto by using intra-vital microscopy video images to demonstrate subcutaneus vasodilation after $\mathrm{CO}_{2}$ administration (3). In addition, $\mathrm{CO}_{2}$ has been shown to increase blood flow rate in the observed subcutaneus vessels (3). Taking advantage of its easy use, low cost and high efficiency, $\mathrm{CO}_{2}$ treatment is used to cure several diseases notably, peripheral arterial and venous disorders (e.g., claudication, lower limb ulcer, etc.), heart diseases (e.g., hypertension, heart failure, etc.) and immunological disorders (e.g., Raynaud's syndrome, Sudeck's disease, etc.) $(4,5)$.

The pathophysiological link between these conditions is the presence of excessive oxidative stress. Investigating the relation between oxidative stress and $\mathrm{CO}_{2}$, Veselá and Wilhelm found $\mathrm{CO}_{2}$ to play a protective role in scavenging free radicals and suppressing oxidative metabolism (6).

Asymmetric dimethylarginine (ADMA) is an endogenous nitric oxide synthase (NOS) inhibitor. Increased plasma ADMA concentrations were shown in patients with classic cardiovascular risk factors (e.g., hypertension, diabetes mellitus, smoking, obesity, etc.) (7, 8). Its outstanding predictive value in cardiovascular risk assessment, already demonstrated by several authors, has been confirmed by a recent systematic review involving nearly 20,000 individuals. Willeit et al. showed a 1.42 risk ratio of adverse cardiovascular disease (CVD) outcomes comparing ADMA values of the top tertile with the bottom tertile $(9,10)$. Furthermore, strong correlations were found between ADMA levels and intima-media thickness and ADMA levels and aortic augmentation index, which are early markers of endothelial dysfunction $(11,12)$. Not only is ADMA capable 
of indicating endothelial dysfunction, but also uncoupling electron transport between NOS and L-arginine. It also inhibits NO formation and induces vascular free radical production leading to increased oxidative stress (13). Accordingly, ADMA is a useful tool for studying the NO system especially in conditions with inflammation and oxidative stress (14).

ADMA is produced intracellularly, as a result of methylated protein degradation, and metabolized mainly by dimethylarginine dimethylaminohydrolase enzyme (DDAH). Expression and function of DDAH is impaired by several conditions, e.g. increased glucose levels, hypercholesterinemia, hyperhomocysteinemia and inflammatory milieu (15). Furthermore, loss of efficiency of DDAH is directly proportional to the severity of oxidative stress (16). In short, ADMA is considered as a marker and mediator of oxidative stress and an indicator of vascular well-being.

\section{Patients and Methods}

Study design. The present study has been performed at our ISO 9001 accredited Cardiology Rehabilitation Inpatient Unit from April 2016 to November 2016. Non-smoker, abstinent, hypertensive patients with an ejection fraction over 55\% were enrolled. Patients who had previously received $\mathrm{CO}_{2}$ therapy were excluded. Moreover, patients who had suffered from myocardial infarction, stroke or undergone open surgery less than a year before the study were also excluded. Additionally, individuals diagnosed with cancer or kidney injury were also excluded. To monitor the changes of plasma ADMA concentrations, blood samples were obtained one hour before and 1 hour, 24 hours and 3 weeks after the first $\mathrm{CO}_{2}$ treatment, respectively. The patients received three transcutaneous $\mathrm{CO}_{2}$ treatments per week for 3 weeks. $\mathrm{CO}_{2}$ gas was administered for 35 minutes in a plastic bag sealed at mid-thoracic level, as previously described by Fabry et al. (4). Clinical data (medical history, age, weight, height, drugs, ejection fraction, laboratory data, etc.), were registered by the same investigator, respectively. Healthy individuals were recruited for the control group. Controls did not undergo $\mathrm{CO}_{2}$ treatment. Only one sample was obtained from controls.

Informed written consent was obtained from every patient. The study protocol was approved by the Regional Ethics Committee of University of Pécs, Pécs, Hungary (Permission No.: 5919.), in accordance with the 2008 Helsinki declaration.

Sampling and measurement of ADMA. Venous blood samples were taken into K-EDTA-containing tubes using a closed blood sampling system (Becton Dickinson Vacutainer; Becton Dickinson, Franklin Lakes, NJ, USA). After centrifugation $(1,500 \times g, 10 \mathrm{~min})$ plasma was collected and stored at $-70^{\circ} \mathrm{C}$ until analysis.

Plasma ADMA concentrations were determined by using enzyme-linked immunosorbent assay (ELISA) method (product No: MBS264847; Mybiosorce, San Diego, CA, USA). The measuring range of the assay was $0.078-5.0 \mu \mathrm{mol} / 1$. Measurements were performed according to manufacturer's protocol.

Statistical analysis. Statistical analysis was performed by IBM SPSS Statistics for Windows Version 22 (IBM Corp., New York, NY, USA). According to Shapiro-Wilk test, ADMA samples showed normal distribution and, thus, error bar was used to demonstrate results (95\% confidence interval for mean). Independent sample $t$ test was used to compare the ADMA levels of patients with those of the ADMA levels of the controls. Differences during the followup were investigated by paired-sample $t$-test. To reveal correlations, the Pearson's correlation test was used. All $p$-values less than 0.05 were considered statistically significant.

\section{Results}

We enrolled 47 patients and 30 controls. Clinical characteristics of the subjects are shown in Table I. Baseline plasma ADMA concentrations were significantly higher in the patients compared to the controls $(0.41 \mu \mathrm{mol} / 1$ vs. $0.35 \mu \mathrm{mol} / \mathrm{l}$; $p=0.018)$. Patients suffering from diabetes mellitus had significantly higher baseline plasma ADMA concentrations compared to non-diabetic patients $(0.47 \mu \mathrm{mol} / 1$ vs. $0.37 \mu \mathrm{mol} / \mathrm{l}$; $p=0.038$ ). Relatively weak but significant positive correlation was found between baseline ADMA levels and age $(p=0.011$, $\mathrm{r}=0.392)$.

ADMA levels decreased significantly one hour after the first $\mathrm{CO}_{2}$ treatment compared to the baseline concentrations ( $p=0.003$; Figure 1). Twenty-four hours after the treatment, ADMA levels increased approximately to the baseline. Comparing ADMA concentrations measured 1 and 24 hours after the first $\mathrm{CO}_{2}$ treatment, a modest but statistically not significant increase was observed. After receiving $9 \mathrm{CO}_{2}$ treatments in an interval of 3 weeks, ADMA levels were found to be modestly lower than the baseline $(p=0.210)$.

We investigated the effects of baseline medication (angiotensin converting enzyme inhibitors (ACEIs), angiotensin II receptor blockers, beta-receptor blockers, diuretics, antidiabetics, antiplatelet therapy, proton pump inhibitors, H2-receptor blockers) on the lowering of ADMA levels that was demonstrated one hour after the first $\mathrm{CO}_{2}$ treatment. Significantly greater reduction was only found among patients in whom ACEIs were administered $(p=0.019)$. Other medications showed no effects on ADMA levels.

\section{Discussion}

In the present study, we investigated the effect of $\mathrm{CO}_{2}$ therapy by monitoring ADMA levels in patients with cardiovascular diseases. The observed baseline elevation in ADMA concentration is probably due to the ongoing disease. Young individuals were enrolled as controls to rule out possible undiscovered diseases that could alter ADMA concentrations. In line with literature data, elevated ADMA levels were found in patients suffering from diabetes mellitus and positive correlation was found between ADMA and age $(7,12)$.

To the best of our knowledge, this is the first study investigating the effect of $\mathrm{CO}_{2}$ treatment on ADMA levels. The prompt decrease of ADMA levels demonstrated 1 hour after $\mathrm{CO}_{2}$ treatment indicates that the treatment had 
Table I. Clinical characteristics of the participants.

\begin{tabular}{lccc}
\hline & $\begin{array}{c}\text { Control group } \\
(\mathrm{n}=30)\end{array}$ & $\begin{array}{c}\text { Patient group } \\
(\mathrm{n}=47)\end{array}$ & $p$-Value \\
\hline Mean age, years & $28 \pm 8.4$ & $67 \pm 12.7$ & $<0.001$ \\
Male, $\mathrm{n}(\%)$ & $13(43)$ & $20(43)$ & 0.808 \\
Diabetes type 2, $\mathrm{n}(\%)$ & - & $18(38)$ & - \\
CABG, $\mathrm{n}(\%)$ & - & $10(21)$ & - \\
MI, $\mathrm{n}(\%)$ & - & $8(17)$ & - \\
BMI, kg/m 2 & $25.2 \pm 3.8$ & $29.1 \pm 4.7$ & 0.706 \\
WBC count, G/1 & $6.53 \pm 1.81$ & $6.12 \pm 1.36$ & 0.238 \\
ADMA 0, $\mu \mathrm{mol} / 1$ & $0.35 \pm 0.07$ & $0.43 \pm 0.03$ & 0.018 \\
ADMA 1h, $\mu \mathrm{mol} / 1$ & - & $0.38 \pm 0.02$ & - \\
ADMA 24h, $\mu \mathrm{mol} / 1$ & - & $0.41 \pm 0.03$ & - \\
ADMA 3w, $\mu \mathrm{mol} / 1$ & - & $0.40 \pm 0.08$ & - \\
\hline
\end{tabular}

CABG, Coronary artery bypass surgery; MI, myocardial infarction; BMI, body mass index; WBC, white blood cells; EF, ejection fraction; ADMA, asymmetric dimethylarginine. Mean \pm SD values are presented.

beneficial effects on the NO pathway, possibly due to vasodilation. Thus, ADMA levels can represent the current vascular state. Such rapid changes have already been reported previously while monitoring ADMA levels during on-pump and off-pump cardiac surgery. The authors related the changes of ADMA concentrations to the intensity of inflammation and oxidative stress (17). After the initial decrease of ADMA concentrations, we observed an increase within 24 hours after the $\mathrm{CO}_{2}$ treatment, which may be due to a rebound effect explained by the subsiding of the vasodilator effect. In a recent study, Bolevich et al. have proved that $\mathrm{CO}_{2}$ is "a universal inhibitor of oxidative stress" (18). Reduced oxidative stress results in an increased efficiency of DDAH leading to decreased ADMA levels (16). In line with these findings, long-term $\mathrm{CO}_{2}$ treatment can decrease the production of reactive oxygen species, which is indicated by the decreasing tendency of ADMA observed after receiving $9 \mathrm{CO}_{2}$ treatments within 3 weeks.

Besides presenting the changes of ADMA levels after $\mathrm{CO}_{2}$ treatment, significantly greater short-term ADMA reduction was found among 25 patients in whom ACEIs were administered. Only a few studies have investigated the relation between ADMA and ACEIs. Veresh et al. showed that ADMA activates the renin-angiotensin-aldosterone system (RAAS), which leads to vasoconstriction and increased oxidative stress (19). Moreover, Ito et al. found reduced ADMA levels among hypertensive patients after being treated with ACEIs (20). Napoli et al. investigated the influence of zofenopril on oxidative stress. ADMA and malondialdehyde (MDA) were used to monitor the oxidative changes. After administering zofenopril, both ADMA and MDA levels decreased. The authors suggest that zofenopril alters the NO pathway and reduces oxidative stress (21).

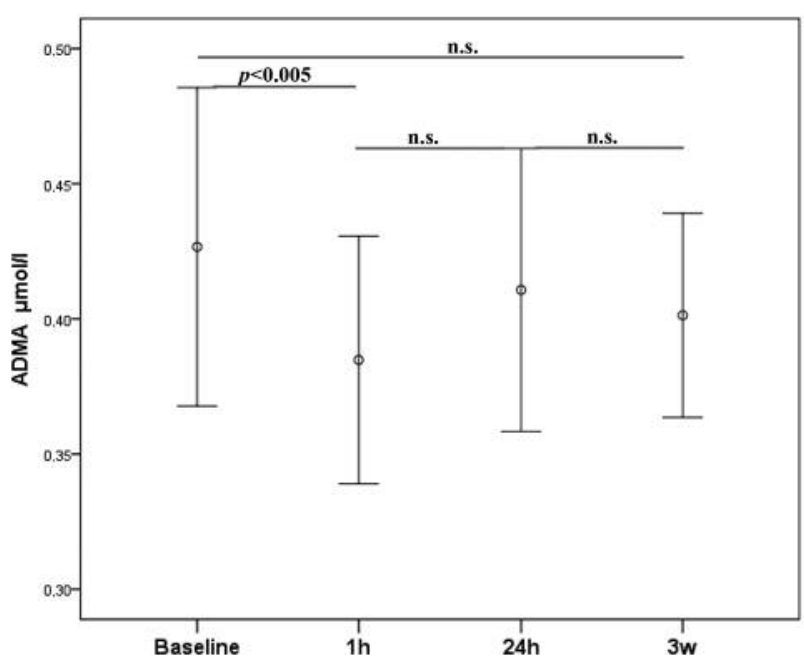

Figure 1. Plasma ADMA levels (mean and $S D$ ) of the involved controls and follow-up of the patients. ADMA, Asymmetric dimethylarginine; n.s., not significant; baseline, before the first $\mathrm{CO}_{2}$ treatment; $1 \mathrm{~h}$, one hour after the first $\mathrm{CO}_{2}$ treatment; 24h, 24 hours after the first $\mathrm{CO}_{2}$ treatment; $3 w$, 3 weeks after the first $\mathrm{CO}_{2}$ treatment.

Moreover, ACEIs have been shown to stimulate NO production through their "bradykinin-sparing" property (22, 23). Interestingly, in the present study, baseline ADMA levels were not shown to be significantly lower in patients receiving ACEIs compared to those without ACEIs. However, according to our results and previous findings, ACE inhibition is not only protective against oxidative stress, but it can also improve vascular reactivity demonstrated by the short-term changes of ADMA after $\mathrm{CO}_{2}$ treatment.

It must be mentioned that this study has certain limitations, such as a relatively small sample size and investigating only ADMA levels. Further research involving more individuals and markers could be useful to examine the relation between $\mathrm{CO}_{2}$ treatment and oxidative stress in more detail.

\section{Conclusion}

The short- and long-term decrease of ADMA levels suggests that $\mathrm{CO}_{2}$ is not only a vasodilator, but also has a beneficial effect on the NO pathway, possibly by reducing oxidative stress. ACE inhibition seems to enhance the beneficial effect of $\mathrm{CO}_{2}$ treatment, most likely due to decreased activation of RAAS and its vasoprotective effects.

\section{Conflicts of Interests}

The Authors declare that there is no conflict of interests regarding the publication of this study. 


\section{Acknowledements}

The Authors wish to thank all the nurses of the Cardiology Unit for their invaluable help in sample collection and, also, Erzsébet Györgyi for her help in the measurements. The present scientific contribution is dedicated to the 650th anniversary of the foundation of the University of Pécs, Hungary.

\section{References}

1 Brandi C, Aniello CD, Grimaldi L, Bosi B, Dei I, Lattarulo P and Alessandrini C: Carbon dioxide therapy in the treatment of localized adiposities: Clinical study and histopathological correlations. Aesthetic Plast Surg 25: 170-174, 2001.

2 Sakai Y, Miwa M, Oe K, Ueha T, Koh A, Niikura T, Iwakura T, Lee SY, Tanaka M and Kurosaka M: A novel system for transcutaneous application of carbon dioxide causing an "Artificial Bohr Effect" in the human body. PLoS One 6: e24137, 2011.

3 Minamiyama $\mathrm{M}$ and Yamamoto A: Direct evidence of the vasodilator action of carbon dioxide on subcutaneous microvasculature in rats by use of intra-vital. J Biorheol 24: 4246, 2010.

4 Fabry R, Monnet P, Schmidt J, Lusson JR, Carpentier PH, Baguet JC and Dubray C: Clinical and microcirculatory effects of transcutaneous $\mathrm{CO}_{2}$ therapy in intermittent claudication. Randomized double-blind clinical trial with a parallel design. Vasa 38: 213-224, 2009.

5 Schmidt J, Monnet P, Normand B and Fabry R: Microcirculatory and clinical effects of serial percutaneous application of carbon dioxide in primary and secondary Raynaud's phenomenon. Vasa 34: 93-100, 2005.

6 Veselá $\mathrm{A}$ and Wilhelm $\mathrm{J}$ : The role of carbon dioxide in free radical reactions of the organism. Physiol Res 51: 335-339, 2002.

7 Cooke JP: Asymmetrical dimethylarginine: The Über Marker? Circulation 109: 1813-1819, 2004.

8 Németh B, Kustán P, Németh Á, Lenkey Z, Cziráki A, Kiss I, Sulyok E and Ajtay Z: Asymmetric dimethylarginine: Predictor of cardiovascular diseases? Orv Hetil 157(13): 483-487, 2016.

9 Willeit P, Freitag DF, Laukkanen JA, Chowdhury S, Gobin R, Mayr M, Di Angelantonio E and Chowdhury R: Asymmetric dimethylarginine and cardiovascular risk: Systematic review and meta-analysis of 22 prospective studies. J Am Heart Assoc 4: e001833, 2015.

10 Schulze F, Lenzen H, Hanefeld C, Bartling A, Osterziel KJ, Goudeva L, Schmidt-Lucke C, Kusus M, Maas R, Schwedhelm E, Strödter D, Simon BC, Mügge A, Daniel WG, Tillmanns H, Maisch B, Streichert $\mathrm{T}$ and Böger RH: Asymmetric dimethylarginine is an independent risk factor for coronary heart disease: Results from the multicenter Coronary Artery Risk Determination investigating the influence of ADMA concentration (CARDIAC) study. Am Heart J 152: 493.e1-e8, 2006.

11 Cakar M, Bulucu F, Karaman M, Ay SA, Kurt Ö, Balta Ş, Demirkol S3, Sarlak H, Akhan M, Altun B, Yaman H, Arslan E, Demirbaş Ş and Sağlam K: Asymmetric dimethylarginine and augmentation index in newly diagnosed patients with hypertension. Angiology 66: 43-48, 2015.
12 Furuki K, Adachi H, Enomoto M, Otsuka M, Fukami A, Kumagae S, Matsuoka H, Nanjo Y, Kakuma T and Imaizumi T: Plasma level of asymmetric dimethylarginine (ADMA) as a predictor of carotid intima-media thickness progression: Six-year prospective study using carotid ultrasonography. Hypertens Res 31: 1185-1189, 2008.

13 Sydow $\mathrm{K}$ and Münzel T: ADMA and oxidative stress. Atheroscler 4(Suppl): 41-51, 2003.

14 Németh B, Kiss I, Péter I, Ajtay Z, Németh Á, Márk L, Csorba A, Kőszegi T, Mühl D and Kustán P: Monitoring of L-arginine and endogenous dimethylarginines in survivor septic patients A pilot study. In Vivo 30: 663-669, 2016.

15 Sibal L, Agarwal SC, Home DP and Boger RH: The role of asymmetric dimethylarginine (ADMA) in endothelial dysfunction and cardiovascular disease. Curr Cardiol Rev 6: 82-90, 2010.

16 Ito A, Tsao PS, Adimoolam S, Kimoto M, Ogawa T and Cooke JP: Novel mechanism for endothelial dysfunction: dysregulation of dimethylarginine dimethylaminohydrolase. Circulation 99: 3092-3095, 1999.

17 Cziráki A, Ajtay Z, Németh Á, Lenkey Z, Sulyok E, Szabados S, Alotti N, Martens-Lobenhoffer J, Szabó C and Bode-Böger SM: Effects of coronary revascularization with or without cardiopulmonary bypass on plasma levels of asymmetric dimethylarginine. Coron Artery Dis 22: 245-252, 2011.

18 Bolevich S, Kogan AH, Zivkovic V, Djuric D, Novikov AA, Vorobyev SI and Jakovljevic V: Protective role of carbon dioxide $\left(\mathrm{CO}_{2}\right)$ in generation of reactive oxygen species. Mol Cell Biochem 411: 317-330, 2016.

19 Veresh Z, Debreczeni B, Hamar J, Kaminski PM, Wolin MS and Koller A: Asymmetric dimethylarginine reduces nitric oxide donor-mediated dilation of arterioles by activating the vascular renin-angiotensin system and reactive oxygen species. J Vasc Res 49: 363-372, 2012.

20 Ito A, Egashira K, Narishige T, Muramatsu K and Takeshita A: Renin-angiotensin system is involved in the mechanism of increased serum asymmetric dimethylarginine in essential hypertension. Jpn Circ J 65: 775-778, 2001.

21 Napoli C, Sica V, de Nigris F, Pignalosa O, Condorelli M, Ignarro LJ and Liguori A: Sulfhydryl angiotensin-converting enzyme inhibition induces sustained reduction of systemic oxidative stress and improves the nitric oxide pathway in patients with essential hypertension. Am Heart J 148: e5, 2004.

22 Hartman JC: The role of bradykinin and nitric oxide in the cardioprotective action of ACE inhibitors. Ann Thorac Surg 60(3): 789-792, 1995.

23 Zhang X, Xie Y-W, Nasjletti A, Xu X, Wolin MS and Hintze TH: ACE inhibitors promote nitric oxide accumulation to modulate myocardial oxygen consumption. Circulation 95: 176-182, 1997.

Received March 17, 2017

Revised April 1, 2017

Accepted April 2, 2017 